\title{
THE EFFECT OF 5-HYDROXYTRYPTAMINE AND 5-HYDROXYTRYPTOPHAN ON EXTRA-PYRAMIDAL FUNCTION
}

\author{
S.HADZ̈OVIĆ * and A.M.ERNST \\ Rudolf Magnus Institute for Pharmacology, Medical Faculty, \\ University of Utrecht, Utrecht, The Netherlands
}

Received 11 September 1968

Accepted 13 January 1969

S.HADŽOVIĆ and A.M.ERNST, The effect of 5-hydroxytryptamine and 5-hydroxytryptophan on extra-pyramidal function, European J. Pharmacol. 6 (1969) 90-95

Intraperitoneal administration of 5-hydroxytryptophan (5-HTP) induced a special form of gnawing behaviour and stereotyped movements of the head and forelegs when given to iproniazid-pretreated rats These effects have not been described previously. Implantation of 5-HT into the rostro-ventral part of the corpus striatum, induced only gnawing behaviour, while only tremor was caused by the implantation of 5-HT or 5-HTP into the substantia nigra. Accordingly, two sites of action of 5-HT were found the rostro-ventral part of the corpus striatum for gnawing behaviour and the substantıa nigra for tremor. To confirm these findings, bilateral lesions were separately made in both these areas and 5 days later, 5-HTP was administered 1.p. (with proniazld pretreatment). The results obtained confurmed the rostro-ventral part of the corpus striatum as the site of action for gnawing behaviour, but they did not confirm the substantia nigra as the only site of action for the tremor.

5-hydroxy tryptamine effect 5-hydroxy tryptophan effect Implantation $\begin{array}{ll}\text { Tremor } & \text { Gnawing behaviour } \\ \text { Lesions } & \text { Stereotyped movements }\end{array}$

\section{INTRODUCTION}

There is much evidence indicating a role for 5-hydroxytryptamine (5-HT) in the brain as a neurohormone (Garattini and Valzelli, 1965). The presence of enzymes for its synthesis and inactivation, its distribution, storage, and release in the brain all suggest that this amine plays an important role in the central nervous system. However, many of the findings concerning its function in the brain are contradictory. Moreover, there are several difficulties in assessing the central effects of serotonin, of which the most important are as follows. The blood-brain barrier is impermeable to the amine (Udenfriend et al.,

* Research-Fellow of the Organization for the Advancement of Pure Research in the Netherlands (Z.W.O.); on leave of absence from the Department of Pharmacology, Veterinary Faculty, University of Sarajevo, Yugoslavia.
1957); the use of the precursor, 5-HTP must be considered critically, since there may be a difference in the effects of 5-HT and 5-HTP (unlike 5-HTP, exogenous serotonin slowly constricts the pupils and does not depress the light reflex (Bogdanskı et al., 1958); 5-HT itself prolongs the reaction time to painful stımulation, whereas 5-HTP is ineffective even in very large doses (Sigg et al., 1958); finally the significance of peripheral and non-specific effects (Erspamer, 1954) is not clear. It was therefore considered that direct implantation of 5-HT or 5-HTP into different parts of the brain of both normal rats and rats pretreated with MAO-inhibitors would be the most satisfactory way of studying their central effects.

It is known that there are some similarities between serotonin and dopamine Both have an effect on the emetic centres, inducing vomitıng (Bogdanski et al., 1958; Peng, 1963); large amounts of both com- 
pounds have been found in the hypothalamus and extrapyramidal system (Bogdanski and Udenfriend, 1956; Bernheimer et al., 1963); there are deficiencies in both 5-HT (Bernheimer et al., 1961, 1963) and dopamine (Ehringer and Hornykiewicz, 1960; Hornykiewicz, 1963) in the extrapyramidal system of Parkinsonian patients, accompanied by a low urinary excretion of homovanillic acid (Barbeau et al., 1961) and of 5-hydroxindoleacetic acid (Barbeau et al., 1963).

However, in rodents which cannot vomit, dopa administration after pretreatment with iproniazid (which increases the content of dopamine in the brain) provokes locomotor excitement followed by intense gnawing behaviour (Ernst, 1965). It therefore seemed of interest to investigate the effect of 5-HTP (which rapidly penetrates the blood-brain barrier and increases the content of 5-HT in the brain) after pretreatment with iproniazid.

Accordingly, experiments were performed to study: (a) whether 5-HTP administration in rats pretreated with iproniazid would similarly provoke gnawing behaviour; and (b) whether direct implantation of 5-HT or of 5-HTP into different parts of the extrapyramidal system would induce similar or different symptoms.

\section{METHODS}

Male albino rats weighing $150( \pm 5) \mathrm{g}$ were used. The experiments were performed in three parts.

(a) Twenty rats were pretreated with $10 \mathrm{mg} / 100 \mathrm{~g}$ of iproniazid, a MAO inhibitor, injected subcutaneously in a concentration of $15 \mathrm{mg} / \mathrm{ml}$ about $16 \mathrm{hr}$ before 5-HTP injection (i.p. $7.5 \mathrm{mg} / \mathrm{rat}$ in a concentration of $7.5 \mathrm{mg} / \mathrm{ml}$ ). After 5-HTP injection the animals were placed in metal cages with a wire-mesh floor on which they were able to gnaw (see Ernst, 1965). Their behaviour was observed for several hours.

(b) Implantations were made bilaterally into the following areas: the caudate nucleus, globus pallıdus, putamen, and substantia nigra. Although the putamen is not well defined in the rat, this term is used to refer to implantations in the rostro-ventral part of the corpus striatum, which corresponds to the putamen in man. The following substances were used for implantation: 5-HT, 5-HTP, apomorphine and eserine as indicated in table 1. Most animals were pretreated with iproniazid as described under (a). A few of them were not pretreated so that a possible difference in the effects of the implanted substances might be seen. The sites of the implantations were always checked macroscopically after the brains had been kept in $4 \%$ formalin solution for $24 \mathrm{hr}$. Sham implantations were made by introduction of the empty cannula. Implantations were made by means of a stainless steel cannula (Ernst and Smelik, 1966). When implantation of a greater amount of the substance $( \pm 200 \mu \mathrm{g})$ had been found to be effective, smaller amounts were then implanted $( \pm 20 \mu \mathrm{g})$ in order to delineate the site of action.

The substances used for implantation were in crystalline form. They were tamped into the cannula and stereotaxically introduced into the above-mentioned areas of the brain under light ether anaesthe-

Table 1

Effect of implantation into rostro-ventral part of corpus striatum.

\begin{tabular}{llclll}
\hline Substances & $\begin{array}{l}\text { No. of impl. } \\
\text { animals }\end{array}$ & Iproniazid & & Number of rats showing: \\
\cline { 3 - 6 } & & & $\begin{array}{l}\text { Gnawing } \\
\text { behaviour }\end{array}$ & $\begin{array}{c}\text { Tremor } \\
\text { Stereotyped } \\
\text { movements }\end{array}$ \\
\hline 5-HT & 23 & + & 23 & 0 & 0 \\
5-HT & 6 & - & 0 & 0 & 0 \\
5-HTP & 6 & + & 0 & 0 & 0 \\
Apomorphine & 6 & - & 0 & 0 & 0 \\
Eserine & 6 & - & 0 & 0 & 0 \\
Sham impl. & 6 & + & 0 & 0 & 0 \\
\hline
\end{tabular}


sia. When the tip of the cannula was in the desired position, the substance was delivered by pushing a stylet down the cannula. After the implantation, the anımals were placed in simlar cages to those used under (a). Their behaviour was observed for several hours.

(c) Bilateral lesions were made separately in the "putamen" and substantia nigra in order to see whether such lesions would prevent the effect of 5-HTP administration (i.p. $7.5 \mathrm{mg} / \mathrm{rat}$ ) after pretreatment with iproniazid. The lesions were made stereoraxically by high frequency cauterization. Recovery tume from surgery was 5 days in most animals, and one day in 13 anımals (rats).

In addition to 5-HTP, 1-dopa (s.c. $10 \mathrm{mg} / \mathrm{rat}$ ) and apomorphine (i.p. $1 \mathrm{mg} / \mathrm{rat}$ ) were also injected in the same rats with lesions in the "putamen".

\section{RESULTS}

(a) Durng the first $15 \mathrm{~min}$ following intraperitoneal injection of 5-HTP into 20 animals, they began sniffing and moving around the cages. Tremor and stereotyped movements of the head and forelegs appeared $10 \mathrm{~min}$ after injection. Gnawing started after about $30 \mathrm{~min}$. This gnawıng behaviour was not like dopamıne- and apomorphıne-gnawing which has been described in an earlier publication (Ernst, 1965), because the anımals gripped the wire of the floor and convulsively held it, all movements around the cage

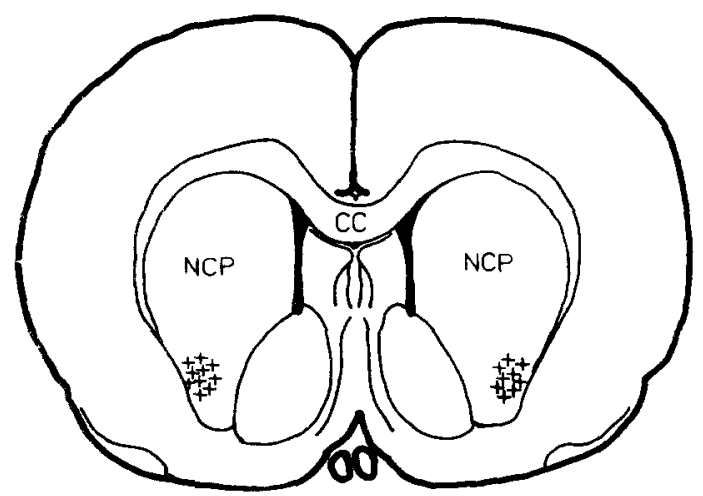

Fig. 1. Implantation site in the rostro-ventral part of the corpus striatum; shown in frontal section. ceasing. During this state tremor and stereotyped movements of the head and forelegs were also marked. These stereotyped movements of head and forelegs were reminiscent of a man playing a prano. Sixty_ninety min after injection the rats gradually recovered.

In the rat netther gnawing behaviour nor stereotyped movements of the head and forelegs have been described previously.

(b) As can be seen from table 1, and figs. 1 and 2, gnawing behaviour was only provoked by the implantation of 5-HT into the "putamen" of the rats which had been pretreated with iproniazid. The sham implantation, and the implantation of 5-HTP, apomorphine or eserine alone into this area had no effect (table 1). The implantation of 5-HT or 5-HTP into all other parts of the corpus striatum induced neither gnawing behaviour nor tremor, even when implanted into the area where the implantation of dopa or apomorphıne does provoke gnawing behaviour (Ernst and Smelik, 1966). The gnawing behaviour induced by 5-HT appeared $65-120 \mathrm{~min}$ after implantation and lasted 50-110 $\mathrm{min}$.

Tremor was induced by the implantation of 5-HT or 5-HTP into the substantia nigra (table 2, and fig. 3) of the rats both with and without iproniazid pretreatment. In all cases tremor appeared 15-100 min after the implantation and lasted 30-150 min. Sham implantation had no effect (table 2).

It is interesting that gnawing behaviour occurred in two cases (table 2) after implantation of 5-HT into

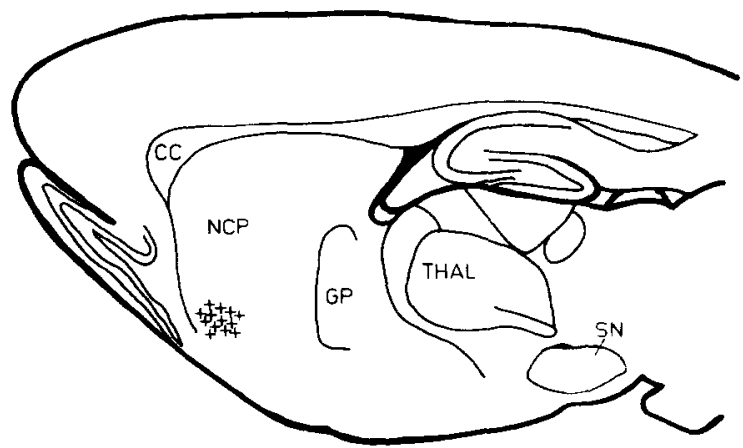

Fig. 2. Implantation site in the rostro-ventral part of the corpus striatum; shown in sagital section. 
Table 2

Effect of implantation into substantia nigra.

\begin{tabular}{|c|c|c|c|c|c|}
\hline \multirow[t]{2}{*}{ Substances } & \multirow{2}{*}{$\begin{array}{l}\text { No. of impl. } \\
\text { animals }\end{array}$} & \multirow[t]{2}{*}{ Iproniazıd } & \multicolumn{3}{|c|}{ Number of rats showing: } \\
\hline & & & $\begin{array}{l}\text { Gnawing } \\
\text { behaviour }\end{array}$ & Tremor & $\begin{array}{l}\text { Stereotyped } \\
\text { movements }\end{array}$ \\
\hline 5-HT & 56 & + & 2 & 42 & 0 \\
\hline $5-\mathrm{HT}$ & 6 & - & 0 & 6 & 0 \\
\hline 5-HTP & 6 & + & 0 & 6 & 0 \\
\hline 5-HTP & 6 & - & 0 & 5 & 0 \\
\hline Sham impl. & 6 & + & 0 & 0 & 0 \\
\hline
\end{tabular}

Table 3

Effect after i.p. administration of 5-HTP, apomorphine and dopa in rats with lesions in the rostro-ventral part of corpus striatum or substantia nigra.

\begin{tabular}{|c|c|c|c|c|c|c|c|}
\hline \multirow{2}{*}{$\begin{array}{l}\text { Injected } \\
\text { substances }\end{array}$} & \multirow{2}{*}{$\begin{array}{l}\text { Lesion } \\
\text { in }\end{array}$} & \multirow{2}{*}{$\begin{array}{l}\text { No. of } \\
\text { animals }\end{array}$} & \multirow{2}{*}{$\begin{array}{l}\text { Days of } \\
\text { rest }\end{array}$} & \multirow[t]{2}{*}{ Iproniazıd } & \multicolumn{3}{|c|}{ Number of animals showing: } \\
\hline & & & & & $\begin{array}{l}\text { Gnawing } \\
\text { behaviour }\end{array}$ & Tremor & $\begin{array}{l}\text { Stereotyped } \\
\text { movements }\end{array}$ \\
\hline 5-HTP & $\begin{array}{l}\text { r.v.p. corp. } \\
\text { striatum }\end{array}$ & 13 & 1 & + & 3 & 13 & 13 \\
\hline 5-HTP & $\begin{array}{l}\text { r.v.p. corp. } \\
\text { striatum }\end{array}$ & 21 & 5 & + & 0 & 21 & 21 \\
\hline Apomorphine & $\begin{array}{l}\text { r.v.p. corp. } \\
\text { striatum }\end{array}$ & 7 & 5 & - & 7 & 0 & 0 \\
\hline Dopa & $\begin{array}{l}\text { r.v.p. corp. } \\
\text { striatum }\end{array}$ & 17 & 5 & + & 17 & 0 & 0 \\
\hline 5-HTP & sub. nigra & 16 & 5 & $\mp$ & 16 & 16 & 16 \\
\hline
\end{tabular}

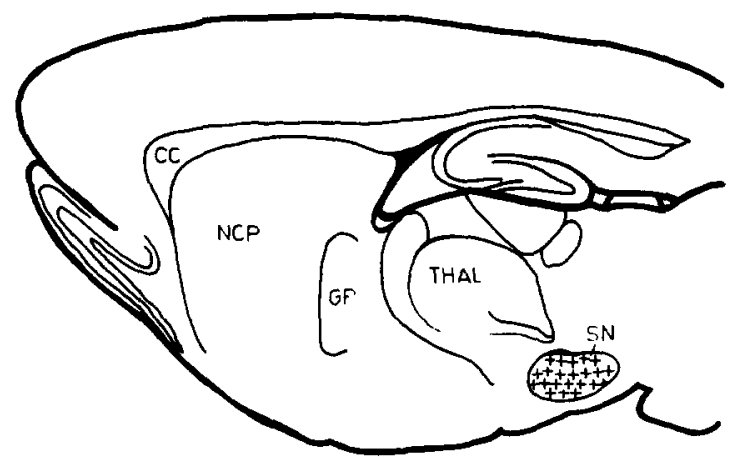

Fig. 3. Implantation site in the substantia nigra; in sagital section. the substantia nigra, but subsequent attempts to repeat this result failed. This explains the large number of rats used.

(c) The results obtained after intraperitoneal administration of 5-HTP, 1-dopa or apomorphine to the rats with lesions in the "putamen" are shown in table 3. 5-HTP induced only tremor followed by stereotyped movements of the head and forelegs, while gnawing behaviour was only provoked after the administration of 1-dopa or apomorphine.

The effect of i.p. 5-HTP administration to rats with lesions in the substantia nigra was surprisingly similar to that in normal animals, 1.e. tremor and other symptoms appeared although the substantra nigra had been destroyed (table 3 ). 


\section{DISCUSSION}

Intraperitoneal injection of 5-HTP evoked all the symptoms previously described in the literature, and in addition caused gnawing behaviour and stereotyped movements of the head and forelegs. Although the effects of 5-HTP have been studied in detall by many authors (Bogdanskı et al., 1958; Garattinı and Valzelli, 1965; Eichler and Farah, 1966; Lewis, 1958, Udenfriend et al., 1957), gnawing behaviour and stereotyped movements of the head and forelegs have never been described. It should be pointed out that gnawing behaviour seen after 5-HTP admınistration was different from that induced by dopa (see Results under (a)).

Results with implantations and lesions clearly show that there are two separate sites of action of 5-HT. The site of action for gnawing behaviour is located in the "putamen" and for tremor in the substantia nigra. However, as has been mentioned, gnawing behaviour was induced in only two rats (out of 56) by the implantation of 5-HT into the substantia nigra. The reason for this finding cannot be explained at the present time, since the majority of the animals (54) did not show this symptom. The implantation of $200 \mu \mathrm{g}$ of $5-\mathrm{HT}$ into the neostriatum - the area where the implantation of dopa or apomorphine provokes gnawing behaviour (Ernst and Smelik, 1966) - also caused gnawing behavıour, but in only 12 out of 20 animals. It is possible that this large amount of 5-HT could spread from the site of the implantation to the putamen which is responsible for the gnawing behaviour. This may be the reason why gnawing behaviour appeared in only 12 out of 20 anımals. However, all further attempts to repeat this result with a $20 \mu \mathrm{g}$ implant failed. It is therefore concluded that the site of action of 5-HT for gnawing behaviour is the "putamen", since this symptom was induced in all cases by the implantation of 5-HT into this area using the small amount, and implantation of the same substance into all other parts of the corpus striatum was without any effect. Other substances, even 5-HTP, when implanted into the "putamen" had no effect. Therefore, the question arises why 5-HTP, unlike 5-HT, was ineffective. There are two possible explanations for this finding possibly there is no 5-HTP decarboxylase in the "putamen", or, accord- ing to Giarman (1956), an excess of 5-HTP in the nervous tissue blocks its enzymatic decarboxylation.

To confirm the finding that the "putamen" is the site of action of 5-HT for gnawing behaviour, the area was destroyed and then 5-HTP i.p. admunistered. After this the substance caused tremor and stereotyped movements, but no gnawing behaviour. The fact that dopa and apomorphine administration to the same anımals induced gnawing behaviour and that these substances implanted into the "putamen" falled to provoke this behaviour, indicates that there is another mechanism for the occurrence of gnawing behaviour in this area.

Tremor was induced by the implantation of 5-HT or 5-HTP into the substantia nigra, while the implantation into the other areas did not induce the symptom. This suggests that the site of action of 5-HT for tremor is the substantia nigra, but the observation that the tremor was induced by i.p. administration of 5-HTP to rats in which the substantia nigra had been destroyed does not support this assumption.

5-HTP had the same effect as 5-HT in the substantia nigra, indicating either that enzymatic decarboxylation may occur in this area despite the findings of Giarman (1956) or that 5-HTP itself can induce the tremor. Which of these two possibilities is correct cannot be decided at present.

Stereotyped movements are also provoked by 5-HT; its site of action will be discussed in a following paper.

\section{REFERENCES}

Barbeau, A., G.Jasmin and Y.Duchastel, 1963, B1ochemistry of Parkinson's disease, Neurology 13, 56.

Barbeau, A., G.F.Murphy and T.L.Sourkes, 1961, Excretion of dopamine in diseases of basal ganglia, Science 133, 1706.

Bernheimer, H., W.Burkmayer and O.Hornykiewicz, 1961, Verteilung des 5-hydroxytryptamines (Serotonin) $1 \mathrm{~m} \mathrm{Ge}-$ hirn des Menschen und sein Verhalten be1 Patienten mit Parkınson-Syndrom, Klın. Wschr. 39, 1056.

Bernhemer, H., W.Birkmayer and O.Hornykıwicz, 1963, Zur Biocheme des Parkınson-Syndroms des Menschen, Klin. Wschr. 41, 465.

Bogdanski, D.F. and S.Udenfruend, 1956, Serotonin and Monoamine oxidase in brain, J. Pharmacol. Exptl. Therap. 116,7 . 
Bogdanski, D.F., H.Weissbach and S.Udenfriend, 1958, Pharmacological studies with the serotonin precursor, 5-hydroxytryptophan, J. Pharmacol. Exptl. Therap. 122, 182.

Ehringer, H. and O.Hornykiewicz, 1960, Vertelung von Noradrenalin und Dopamin (3-Hydroxytyramin) im Gehirn des Menschen und ihr Verhalten bei Erkrankungen des extrapyramidalen System, Klin. Wschr. 38, 1236.

Eichler, O. and A.Farah, 1966, Handbook of experimental pharmacology, vol. XIX (Springer Verlag, Berlun).

Ernst, A.M., 1965, Relation between the action of dopamine and apomorphine and their 0-methylated derivatives upon the CNS, Psychopharmacologia 7, 391.

Ernst, A.M. and P.G.Smelik, 1966, Site of action of dopamine and apomorphine on compulsive gnawing behaviour in rats, Experientia 22, 837.

Erspamer, V., 1954, Pharmacology of indolealkylamines, Pharmacol. Rev. 6, 425.
Garattini, S. and L.Valzelli, 1965, Serotonin (Elsevier Publishıng Company, Amsterdam).

Giarman, N.J., 1956, Biosynthesis of 5-hydroxytryptamıne (serotonin, enteramine) Fed. Proc. 15, 428.

Hornykiewicz, O., 1963, Die topische Lokalisation und das Verhalten von Noradrenalin und Dopamin (3-Hydroxytyramin) in der Substantia Nigra des normalen und Parkinsonkranken Menschen, Wien. Klin. Wschr. 75, 309.

Lewis, G.P., 1958, 5-Hydroxytryptamine, Proc. London symposium 1st and 2nd April, 1957 (Pergamon Press, London).

Peng, M.T., 1963, Locus of emetic action of epinephrine and dopa in dogs, J. Pharmacol. Exptl. Therap. 139, 345.

S1gg, E.B., G.Caprio and J.A.Schneider, 1958, Synergism of amines and antagonısm of reserpine to morphine analgesia, Proc. Soc. Exptl. Biol. (N.Y.) 97, 97.

Udenfriend, S., H.Weissbach and D.F.Bogdansk1, 1957, Biochemical findings relating to the action of serotonin, Ann. N.Y. Acad. Sc1. 66, 602. 